\title{
TEAM-BASED LEARNING VS LECTURE-BASED LEARNING IN MEDICAL EDUCATION
}

\author{
ASFIA IRFAN ${ }^{1}$, SANA NAZ ${ }^{2}$, ZAHID MEHMOOD ${ }^{3}$, ZEHRA NASEEM $^{3}$, KANWAL NAZ ${ }^{3}$, SAAD ABDUL RAZZAK
}

${ }^{1}$ National Medical Centre. ${ }^{2}$ Suleman Roshan Medical College. ${ }^{3}$ Postgraduate Medical Centre Karachi. E-mail: drzmpk@yahoo.com

Received: 11 February 2021, Revised and Accepted: 08 July 2021

\section{ABSTRACT}

Objective: The objective of the study is to determine better mode of learning for medical graduates by comparing team-based learning (TBL) and lecture-based learning methods.

Study Design: Comparative analytical study.

Place and Duration of Study: Surgical Ward 25 of Endocrine and General surgery, Jinnah Postgraduate Medical Center, Karachi, in April 2019.

Methodology: This comparative study was based on the principles of TBL; the control program used the traditional lecture-based approach Both programs were aimed at investigating the knowledge and performance of the two groups. Thirty surgical interns were included in this study. Two groups were made by random selection of surgical interns, 15 in TBL group and other 15 in traditional teaching group. TBL group (Group A) was given the topic of thyroid diseases for self-study followed by $1 \mathrm{~h}$ discussion amongst the group members. Lecture-based group (Group B) was given $1 \mathrm{~h}$ powerpoint presentation on similar topic. As the main outcome measures, questionnaire containing twenty best choice questions was given to both groups. Performance of the two groups was checked and results calculated as total, average, and standard deviation.

Results: Group A participants' total score (147) was higher than Group B (131) but the p-value was not found to be significant (0.144).

Conclusion: Both forms of learning methods are effective and productive in medical education.

Keywords: Team based learning, Lecture based learning, Medical Education.

(C) 2021 The Authors. Published by Innovare Academic Sciences Pvt Ltd. This is an open access article under the CC BY license (http://creativecommons org/licenses/by/4.0/) DOI: http://dx.doi.org/10.22159/ijms.2021v9i5.41064. Journal homepage: https://innovareacademics.in/journals/index.php/ijms

\section{INTRODUCTION}

Medical education is a broad spectrum where various methods have been practiced to bring improvement in the knowledge and learning skills of medical students. Several advances are being made toward innovation in medical education and many countries worldwide are engaged in examining and updating their educational strategies [1] The traditional method of teaching in medical education has been lecture-based where tutor delivers prepared lecture on a particular topic mostly on multimedia. This method of learning is helpful in covering vast medical syllabus in timely fashion by the medical school. However, due to the lack of interaction between tutor and students and lack of discussion of clinical problems and scenarios among students themselves, lecture-based learning method has not been as productive as per the requirement.

The attractiveness of team-based learning (TBL) as a learner-centered, interactive educational approach has prompted many to adopt this method in under and postgraduate education [1]. Active participation of pupils in sessions and their continuous feedback during solving clinical scenarios helps in better understanding and gain of knowledge of the entire team.

In this study, we compared the two methods (lecture-based and TBL) of imparting medical education and determine which method is better and more productive. The purpose of this review is to provide a benchmark that faculty and academic planners can use to assess performance through learning experiences associated with the development of problem-solving, critical thinking, self-directed learning, and other cognitive skills necessary for medical school graduates to ultimately become better performers as they develop professionally in the years after graduation $[2,3]$.

\section{METHODOLOGY}

This comparative study was conducted at Surgical Ward-25, Department of Endocrine and General Surgery, Jinnah Postgraduate Medical Center, Karachi. 30 surgical interns were included in this study. Two groups comprising of 15 interns each were made by means of a random number table and block randomization to account for equal allocation of participants to the groups.

Group A was the study group who were supposed to participate in the TBL method. Group B was the lecture-based learning group.

Group A was given the topic benign and malignant diseases of thyroid for discussion a day before and were given a period of $1 \mathrm{~h}$ for team discussion. Group B was given lecture on multimedia on the same topic for $1 \mathrm{~h}$ by two postgraduate trainees of our ward.

The two groups were given a BCQ test containing 20 questions. This test was prepared by another member of our team and the PGs giving lecture to group B were not shown this test paper to keep the experiment double-blind. Both groups were given $30 \mathrm{~min}$ to complete the test.

\section{RESULTS}

The gain in knowledge remained positive [4]. Scores of participants of group A and B were added. Group A scored 147 out of 300 and Group B scored 131 out of 300 . Highest score in Group A was 14 and lowest was 5. Highest score in Group B was 12 and lowest was 4. Group A average was $9.8 \pm 2.54$. Group B average was found to be $8.73 \pm 2.86$. The detail of result is shown in following Table 1 : 
Table 1: Result of participants

\begin{tabular}{lll}
\hline Serial no. & Group A & Group B \\
\hline 1 & 10 & 12 \\
2 & 6 & 12 \\
3 & 12 & 11 \\
4 & 7 & 9 \\
5 & 11 & 10 \\
6 & 11 & 7 \\
7 & 11 & 9 \\
8 & 9 & 5 \\
9 & 5 & 7 \\
10 & 12 & 12 \\
11 & 12 & 6 \\
12 & 8 & 10 \\
13 & 14 & 12 \\
14 & 11 & 5 \\
15 & 8 & 4 \\
\hline
\end{tabular}

\section{DISCUSSION}

Case-based, TBL models have been used in many teaching strategies in recent years. Interactive teaching/learning methods such as TBL and case-based learning can impart sustainable knowledge and performance change and lead to high satisfaction among students as compared with conventional lecture-based classes as suggested by studies. However, medical and dental students are accustomed to the conventional lecture style such as listening to a lecturer, viewing PowerPoint presentations, receiving handouts and taking notes. Generally, these large lecturebased classes are no longer viewed as the ideal method for creating indepth and long-lasting understanding of the subject matter learned by students [5].

The process of developing the capacity for good clinical judgment and skillful on-the-job performance typically extends well beyond the temporal confines of in-school education $[2,4]$. TBL enables medical graduates to share knowledge, enhance their clinical acumen, promote critical thinking and acquire productive communication skills. To develop the problem-solving ability, students must convert the unorganized static information they have gathered from textbooks and lectures into the interlinked chains of networked knowledge, defined as information that has meaning, value, and recognized utility and which an individual can explain in his or her own words [2]

The original ideology of problem-based learning (PBL) was built upon the concept that its participants would be of a more mature age, and with personal and potential qualities that would enable them for problem-solving as part of their learning process. However, despite global acceptance for the use of PBL in medical and health sciences education, structured programs preparing medical students for such an educational activity are not common [6].

There has been a shift from pure classroom lecture environments to active learning that requires participation by students as they participate in real clinical scenarios. The goal is to shift to a problemand case-based learning methodology and student-centered instructional models to achieve the kind of learning that requires the critical thinking and problem-solving skills needed for professional practice $[3,7,8]$.
We studied the effect of two learning strategies (team-based and lecture-based) in medical education. Both were effective in improving knowledge and performance, but performance increased more in the team-based group [4]. TBL is increasingly used in higher education because it involves active learning to enhance self-directed learning (deep learning) and student adaptability in problem-solving situations. Deep learning results in greater retention of the material, likely because students understand and make personal sense of the material, rather than simply memorize and reproduce it [9].

Another observation made during conduction of this study was the attitude of participants towards the two methods of learning. TBL group was found to be less confident as compared to the lecturebased group when appearing for the test. This indicates the lack of acquaintance of practice of team-based and problem-based learning methodology in our system. In addition, students reported that more preparation was required for sessions where self-based learning is emphasized. Tutors were able to modify their role and influence group processes in a controlled manner [10]. Therefore, through this study, we recommend active introduction of this methodology in our current medical education system to encourage better performance at both under and postgraduate levels.

\section{CONCLUSION}

The results of this study conclude that both forms of learning methods are effective and productive in medical education. As per score of the test conducted upon the two groups, Group A (team-based group) scored higher than Group B (lecture-based group) but statistically, the difference between the two methods is not found to be significant.

\section{REFERENCES}

1. Al-Azri H, Ratnapalan S. Problem-based learning in continuing medical education: Review of randomized controlled trials. Can Fam Physician 2014;60:157-65

2. Hendricson WD, Andrieu SC, Chadwick DG, Chmar JE, Cole JR, George MC, et al. Educational strategies associated with development of problem-solving, critical thinking, and self-directed learning. J Dent Educ 2006; 70:925-36

3. Frame TR, Cailor SM, Gryka RJ, Chen AM, Kiersma ME, Sheppard L. Student perceptions of team-based learning vs traditional lecture-based learning. Am J Pharm Educ 2015;79:51.

4. Smits PB, de Buisonjé CD, Verbeek JH, van Dijk FJ, Metz JC, ten Cate OJ. Problem-based learning versus lecture-based learning in postgraduate medical education. Scand J Work Environ Health 2003;29:280-7.

5. Shetty SR, Babu GS, Castelino R, Hegde S, Rao PK, Kishor S. Casebased, team-based learning: A novel method for teaching orofacial syndromology to dental undergraduate students. Educ Health (Abingdon) 2015;28:112-3.

6. Abdelkhalek N, Hussein A, Gibbs T, Hamdy H. Using team-based learning to prepare medical students for future problem-based learning. Med Teach 2010;32:123-9.

7. Kumar V, Gadbury-Amyot CC. A case-based and team-based learning model in oral and maxillofacial radiology. J Dent Educ 2012;76:330-7.

8. Engel FE, Hendricson WD. A case-based learning model in orthodontics. J Dent Educ 1994;58:762-7.

9. Moore TS. Implementation of problem-based learning in a baccalaureate dental hygiene program. J Dent Educ 2007;71:1058-69.

10. Gerhardt-Szep S, Kunkel F, Moeltner A, Hansen M, Böckers A, Rüttermann $\mathrm{S}$, et al. Evaluating differently tutored groups in problembased learning in a German dental curriculum: A mixed methods study. BMC Med Educ 2016;16:14. 